\title{
UMA TRAJETÓRIA DE CONQUISTAS: BREVES NOTAS SOBRE A ATUAÇÃO DE UM CENTRO DE APOIO PEDAGÓGICO COM ALUNOS AUTISTAS
}

\section{A path of achievements: brief notes about the performance of a pedagogical support center with autistic students}

Solange Barboza Bastos - Centro de Apoio Pedagógico/ Brasil Antonia Vieira Santos - Universidade do Estado da Bahia/Brasil

RESUMO: Este estudo tem como objetivo discutir a trajetória de alunos com Transtorno do Espectro Autista (TEA) que recebem Atendimento Educacional Especializado (AEE) em um Centro de Apoio Pedagógico (CAP) no interior da Bahia; a discussão é dada a partir do modo como acontece a interação entre aluno, família e professor de AEE e o modo como esse processo contribui para o desenvolvimento do processo ensinoaprendizagem dos estudantes com TEA. A metodologia que guiou esse trabalho transita na modalidade de pesquisa qualitativa, sendo o ponto de partida as entrevistas semiestruturada, cujo relatos descrevem a trajetória dos atendimentos do ano de 2009 até 2019: os desafios no processo de aprendizagem e inclusão, as capacitações dos professores, as parcerias com a famílias, projetos e experiências exitosas. Com os resultados é possível constatar os desafio do CAP no AEE aos sujeitos alunos autistas, assim como as dificuldades a serem superadas na interação entre escola-aluno-família e a necessidade de busca por novas ferramentas com base em estudos e pesquisas que favoreçam o desenvolvimento das potencialidades dos sujeitos autistas que adentram um CAP e se seus professores.

Palavras-chave: Autismo; Centro de Apoio Pedagógico; Atendimento Educacional Especializado.

ABSTRACT: This study aims to discuss the trajectory of students with Autism Spectrum Disorder (TEA) who receive Specialized Educational Assistance (AEE) at a Pedagogical Support Center (CAP) in the interior of Bahia; the discussion is based on the way in which the interaction between student, family and ESA teacher happens and the way this process contributes to the development of the teaching-learning process of students with ASD. The methodology that guided this work is carried out in the qualitative research modality, the semi-structured interviews being the starting point, whose reports describe the trajectory of the services from 2009 to 2019: the challenges in the learning and inclusion process, the training of teachers, partnerships with families, projects and successful experiences. With the results it is possible to verify the challenges of the CAP in the ESA to the autistic student subjects, as well as the difficulties to be overcome in the interaction between school-student-family and the need to search for new tools based on studies and research that favor the development the potential of autistic subjects who enter a CAP and their teachers.

Keywords: Autism; Pedagogical Support Center; Specialized Educational Service.

\section{INTRODUÇÃO}

Educação, Psicologia e Interfaces, Volume 4, Número 2, p. 108-122, Abril/Junho, 2020. 
Uma trajetória de conquistas: breves notas sobre a atuação de um Centro de Apoio Pedagógico com alunos autistas

A Educação Especial ao longo dos anos passou por transformações. Muitos movimentos sociais se organizaram na busca de equidade e condições favoráveis para que a inclusão de alunos com Necessidades Educacionais Especiais (NEE) se concretizasse, e a escola regular assumisse a responsabilidade por todas as etapas do processo de aprendizagem desses alunos (KASSAR, 2012; GARCIA, 2013).

Nesta perspectiva, o Brasil busca através da Política Nacional de Educação Especial e Educação Inclusiva (BRASIL, 2008), um compromisso para o acesso e permanência do aluno com NEE, garantindo assim uma educação que respeite e dê espaço para a alteridade. Com esse avanço percebeu-se um aumento significativo na diversidade de alunos matriculados na rede regular, alunos com deficiência, transtornos globais do desenvolvimento (TGD), altas habilidades/superdotação.

Dentro do grupo do TGD, trataremos aqui do transtorno do espectro autista (TEA), ou seja, da assistência no AEE para alunos autistas atendidos pelo ensino regular. Na atualidade são muitas as publicações e pesquisas acerca dos modos de lida com o TEA, no entanto essas mesmas pesquisam evidenciam um desconhecimento sobre sua etiologia, dificuldades no diagnóstico e apostas no prognóstico. Assim, muitas dificuldades surgem nas instituições de ensino sobre as manifestações, comportamentos, metodologia adequada para o ensino aprendizagem de alunos no espectro autista. Todas essas frechas e dúvidas quanto a caminhada com o TEA torna a atuação do professor um desafio para o trabalho com os alunos autistas.

A primeira descrição de autismo foi feita no ano de 1943 pelo psiquiatra americano Leo Kanner. Nesse estudo, Kanner descreve características de algumas crianças que estavam sobre sua terapia e apresentavam-se com comportamentos limitados ao interesse, insistência em rotinas e comportamentos repetitivos. Daí a origem grega da palavra autismo designando a auto absorção. Definições posteriores centraram-se na tríade de comprometimento: isolamento social, dificuldade de comunicação e insistência na repetição. Outros estudos se baseiam na díade: comprometimento na interação social e na comunicação (FERREIRA; VORCARO, 2016).

O comportamento restrito, repetitivo e estereotipado são características marcantes nos sujeitos autistas. Repetições motoras como bater as mãos, pular, rodar objetos, fazer movimentos repetitivos com o corpo, embora sejam atividades comuns em crianças sem 
autismo, são também sinais presentes e bastantes observáveis nas crianças com autismo. Para Chris Williams (2008, p. 03).

Distúrbios do Espectro do Autismo (Autisc Spectrum Disorder - ASD) é um distúrbio do desenvolvimento que normalmente surge nos primeiros três anos de vida da criança. [...]. Não é algo que a criança pode contrair. Não é causado pelos pais. É uma condição que prossegue até a adolescência e vida adulta. Contudo, todas as crianças com ASD continuarão a demonstrar progresso no desenvolvimento; há muito que pode ser feito para ajudá-las.

Nesses últimos anos muitas foram as divulgações de conhecimentos no campo científico, apresentando especificidades e modos possíveis de intervenções com o TEA. No entanto, todos se deparam com o enigma do autismo, apresentando poucos avanços e trazendo angustia para os pais, cuidadores e educadores, que ficam perdidos em meio a tantas informações sem saber qual ou quais caminhos seguir. Filippo Muratori (2014, p.10) afirma ainda que:

O autismo é habitualmente caracterizado pela permanência num isolamento, pela repetição de ações motoras e pelos interesses restritos. Esse último aspecto clínico está relacionado com a frequência da presença, nas crianças com autismo, dos distúrbios sensoriais (seja no sentido de uma hiper-reatividade ou, mais frequentemente, no sentido de uma hiporreatividade) que podem se referir, de forma variada, a todos os órgãos do sentido (tato, olfato, gustação, visão, audição e também a propriocepção).

Chamamos atenção nesse trabalho, para o entendimento do modo como se dá o processo de aprender da criança autista no CAP, as possibilidades de intervenção do professor, ações e movimentos, chamados de auto estimulantes, que podem ser facilitadores na redução de ansiedade, o que pode ser causado por excessos de informações que chegam de forma variada a criança autista na escola e interferem no comportamento e aprendizagem dessas crianças.

Esse estudo se constrói, então, com o objetivo de discutir a trajetória dos alunos com Transtorno do Espectro Autista, no Atendimento Educacional Especializado em um Centro de Apoio Pedagógico localizado no interior da Bahia. A definição do tema partiu da necessidade de analisar a importância, as contribuições e os resultados obtidos nos anos de atendimento de sujeitos autistas e refletir sobre os processos de ensino aprendizagem com esses estudantes nessa instituição.

Educação, Psicologia e Interfaces, Volume 4, Número 2, p. 108-122, Abril/Junho, 2020. 
Uma trajetória de conquistas: breves notas sobre a atuação de um Centro de Apoio Pedagógico com alunos autistas

O trabalho está organizado de maneira a expor brevemente as concepções sobre o autismo, a partir da teorização transmitida no campo da ciência e da concepção de professores, articuladores de área e equipe gestora do CAP, cedidas através de entrevistas. Para a discussão fez-se necessário uma compreensão do tempo de atendimento na instituição; quantidade de alunos atendidos com diagnóstico médico ou sinalização da escola regular, a proposta pedagógica do CAP; seus objetivos; as relações e os desafios enfrentados no AEE; e forma de funcionamento dos atendimentos.

Como base de pesquisa para esse trabalho contamos com o apoio do Projeto Político Pedagógico do CAP elaborado no ano de 2010 e com última atualização no ano de 2018. Este documento traz o histórico da instituição, sua missão, o diagnóstico da realidade contextual, e entre outros assuntos os princípios norteadores dos trabalhos ali desenvolvidos. Essa pesquisa se deu como modo possível de compreender como o CAP vem contribuindo ao longo desses anos no atendimento ao autista, na interação com os grupos de apoio a esses sujeitos, seus familiares e professores.

Essa pesquisa perpassa ainda pela experiência da primeira autora com alunos autista dentro de um tempo estimado de 4 anos nesse CAP, como mediadora da aprendizagem. Oportunidade de estudar mais detalhadamente e se envolver no universo de emaranhados de descobertas sobre nomenclatura, características, diagnósticos e sobretudo das possibilidades na intervenção no processo de ensino-aprendizagem.

Somou-se a sua experiência para a escrita sua participação no projeto de pesquisa e extensão: Construindo redes: apoio a inclusão escolar de crianças no transtorno global do desenvolvimento, projeto coordenado pela segunda autora desse trabalho que aconteceu nos anos de 2017 e 2018 ininterruptos na Universidade do Estado da Bahia (UNEB) Campus XXI.

A esperança é que esse estudo enriqueça os leitores, aproximando-os de uma realidade que vem ganhando espaço e desencadeando ações benéficas a um grupo de alunos autista na Região do Território Médio Rio das Contas na Bahia.

\section{O PERCURSO METODOLÓGICO}

Para a construção desse trabalho pressupôs uma abordagem metodológica qualitativa alicerçada na possibilidade de problematizar os fatos em toda sua

Educação, Psicologia e Interfaces, Volume 4, Número 2, p. 108-122, Abril/Junho, 2020.

ISSN: 2594-5343. DOI: $10.37444 /$ issn-2594-5343.v4i2.237 
complexidade. Acreditamos que esta forma de pesquisa se defina como a mais apropriada para acompanhamento e análise da problemática aqui explicitada.

Em nosso itinerário nos desafiamos a desenvolver um estudo de caso com vistas ao entendimento de que não foi nosso objetivo avaliar as práticas dos professores, nem oferecer sugestões de práticas exitosas, mas a partir das observações, registros e entrevistas, contribuir com uma reflexão sobre a prática desenvolvida por estes professores, problematizando o "lugar" de onde falam e as subjetividades implícitas em suas escolhas, definição de critérios e práticas pedagógicas em atendimento às diferenças de crianças no TEA no espaço de um CAP (PIMENTA, 2006).

Ao buscar coerência com os pressupostos metodológicos adotados é que as técnicas utilizadas transitaram por entrevistas, observações e registros em diário que de forma integrada proporcionaram a compreensão dos paradoxos do ensino e da aprendizagem de crianças autistas.

Como campo de pesquisa tivemos o cenário de um Centro de Apoio Pedagógico, localizado no Território Médio Rio das Contas, sul da Bahia. A cidade que sedia o campo de pesquisa se constitui em um polo para outras cidades menores e representa um lugar para diversas atividades na área do comércio, da saúde e também da educação.

O Centro de Apoio Pedagógico aqui em discussão foi criado no ano de 2009 numa ação do Governo do Estado da Bahia atendendo a uma proposta do Ministério da Educação e Cultura (MEC), que designa as unidades com este formato de Centro de Atendimento Educacional Especializado, com atuação complementar ou suplementar ao ensino regular. Prioriza no seu atendimento ao aluno o AEE e também ações que promovam sua inclusão sócio educacional através de: recursos pedagógicos e tecnológicos; professores especializados que atendam alunos com diferentes demandas gerado pela Deficiência, TGD e Altas Habilidades/Superdotação; formação de profissionais na área da Educação Especial e orientação às famílias.

O CAP se constrói cotidianamente como um espaço que assegura um atendimento pedagógico especializado e de qualidade, garantindo o acesso e a permanência dos alunos com NEE na escola, a fim de valorizar as diferenças, fortalecer a autonomia e favorecer a inserção desses alunos, nos diversos ambientes sociais.

Para além de se constituir como centro de atendimento educacional especializado, o CAP se caracteriza, também, como modalidade de educação transversal, uma vez que 
Uma trajetória de conquistas: breves notas sobre a atuação de um Centro de Apoio Pedagógico com alunos autistas

a educação especial perpassa os vários níveis de ensino, e diferencia-se essencialmente da escolarização, constituindo ambiente propício à socialização e à construção do conhecimento. Os alunos são distribuídos por áreas pedagógicas a depender das dificuldades/deficiências detectadas e/ou necessidades educacionais diagnosticadas, considerando as competências e habilidades a serem desenvolvidas.

No CAP, campo dessa pesquisa, as áreas de atendimento são divididas em: altas habilidades/superdotação; deficiências (deficiência visual, surdez, intelectual) e transtorno do espectro autista. Cabendo ao atendimento psicopedagógico a triagem dos alunos e o diagnóstico inicial.

$\mathrm{Na}$ construção desse trabalho tivemos a colaboração de três profissionais que atuam diretamente com as crianças autistas, duas professoras e a secretária da instituição. Vale salientar que as colaboradoras assinaram o termo de consentimento livre e esclarecido (TCLE). No decorrer do trabalho não utilizamos os nomes das profissionais, no intuito de proteger suas identidades, com isso, usaremos para identificá-las a letra $\mathrm{P}$ de profissional acrescidos da numeração 1, 2 ou 3, referente ao número de entrevistadas, sendo possível a identificação das profissionais apenas pelas pesquisadoras.

O contato com a secretaria na instituição, permitiu as pesquisadoras conhecer os aspectos administrativos: matricula, recebimento de documentação (escolar e médica), encaminhamentos dos relatórios para as escolas regulares ou órgãos competentes, e também o quantitativo de alunos que ano a ano passam na Instituição.

As entrevistas realizadas foram gravadas e em seguida transcritas, tendo o cuidado em ser fidedigna no registro dos discursos, visando captar as dificuldades, os enfrentamentos, as ações que facilitam o atendimento, todo o processo pedagógico envolto com o aluno autista. Essa opção pela coleta de dados via entrevista foi orientada pelo pressuposto de que as informações ali colhidas com as professoras teriam profundidade para discutir como os alunos autistas são atendidos e se relacionam com a comunidade escolar.

Como técnica de análise dos dados se lançou mão da análise do discurso (AD) de origem francesa. Koch (2005) afirma que o sentido não está no texto, mas se constrói a partir dele. Para se entender as entrelinhas daquilo que está dito faz-se necessário processos e estratégias cognitivas e interacionais, no qual um texto dialoga com o outro, 
e o lugar do outro é a interpretação. O sentido do discurso é carregado de ideologias que podem mudar o sentido das palavras daqueles que as empregam.

Os aspectos norteadores das informações colhidas são fundamentais para a interpretação, análise e conclusão de como o CAP vem ao logo desses quase dez anos de trabalho colaborando para que os alunos com TEA tenham um atendimento educacional especializado de qualidade, e de como essa instituição tem contribuído para o estabelecimento de uma rede de atendimentos as famílias e a comunidade em geral.

\section{RESULTADOS E DISCUSSÃO}

Pensar em inclusão escolar é pensar em ações que promovam ambiente e currículo adaptado, disponibilidade de recursos pedagógicos, profissionais capacitados, numa perspectiva de inserir para promover um trabalho de qualidade, permitindo que cada autista, a seu tempo consiga um desenvolvimento sócio-psico-afetivo.

É comum que os pais caiam na armadilha de apontar apenas os comportamentos problemáticos das crianças. Ao fazerem isso, podem perder de vista as habilidades e os pontos fortes que elas possuem. Quais são os dons e habilidades inatas de seus filhos? Após identificarem essas áreas, é possível estimular e direcionar seus talentos e potencialidades de forma correta (SILVA, 2012, p. 45).

A inclusão é vista como um meio para uma convivência com os diversos no contexto escolar de forma a desenvolver o ser, o pensar, o sentir, onde todos possam aprender e todos possam ensinar. Se pensamos em um ambiente e um currículo adaptado consideramos pertinentes ações que estabeleçam estímulos afetivos, sensoriais e cognitivos em sintonia com a história familiar e social, suas necessidades, seus desejos, que conduzirão todo o processo de aprendizagem. Transformar as ações em práticas pedagógicas ricas e prazerosas para o aprender é e sempre será um desafio no trabalho de inclusão.

Acima de tudo, deverá prevalecer a virtude de saber esperar, não por resultados imediatos, mas por conquistas. E a primeira delas é o vínculo afetivo. Para isso, o professor deve priorizar seu aluno. Essa escolha expressa a opção por ações que sejam mais adequadas a ele, flexíveis pela necessidade de aprendizagem (CUNHA, 2011, p. 54).

É importante compreender que o planejamento das atividades deve partir do campo de interesse do aluno, permitindo que o professor se aproprie de técnicas e essas

Educação, Psicologia e Interfaces, Volume 4, Número 2, p. 108-122, Abril/Junho, 2020. 
Uma trajetória de conquistas: breves notas sobre a atuação de um Centro de Apoio Pedagógico com alunos autistas

sejam usadas para compreender suas limitações a serem trabalhadas e seu potencial. Considerando essa modalidade de pensar o processo de ensino da criança autista e do atendimento no CAP apresentamos a seguir as três categorias de análise.

\subsection{Acesso e permanência de estudantes com TEA no AEE.}

No AEE o professor precisa de formação específica para atender a especificidade do aluno, tendo a função de intervir como mediador e articulador; acompanhando e orientando as demandas do professor da escola regular; promovendo o atendimento que pode ser individualizado ou em pequenos grupos; utilizando recursos e tecnologias que complementem ou suplementem as atividades a serem desenvolvidas (BAHIA, 2017, p. 48).

Estes atendimentos ao logo dos anos vem evidenciar o quanto é importante permitir o acesso e permanência desses alunos autista no ambiente escolar. É interessante compreender como esse processo se formou, quando iniciou e seu aumento gradativo.

Inicialmente, no ano de 2009 o CAP recebeu seus primeiros alunos no espectro autista, foi através destes dois alunos evidenciados na fala da professora P2 que os atendimentos começaram, certos de que muitos impasses surgiriam, houve a necessidade de buscar informações, literaturas e capacitações para que o atendimento não ficasse a quem da necessidade dos alunos.

Começamos a receber meninos que, apoiado nos estudos, manifestavam comportamento de autismo. Como foi o caso dos primeiros alunos nossos, inclusive um caso de dois irmãos gêmeos que sempre conversávamos com a família que eles manifestavam características de TDAH, muitas vezes de Dificuldade de Aprendizagem, mas muitos comportamentos típicos de autismo (P2).

Nos anos seguintes de funcionamento, oferta de acolhimento e atendimento as crianças e suas famílias, a procura pelo serviço só aumentou, o que é bastante representativo no número de matriculas. De acordo aos dados cedidos pelo CAP no ano de 2009 apenas dois alunos com TEA estavam sendo atendidos no CAP e esse número vem aumentando gradativamente chegando ao expressivo de doze alunos em 2014. 2017 o CAP se abre a atender alunos vindos de cidades vizinhas, fato que eleva o número de matriculados em 2019.

Educação, Psicologia e Interfaces, Volume 4, Número 2, p. 108-122, Abril/Junho, 2020.

ISSN: 2594-5343. DOI: $10.37444 /$ issn-2594-5343.v4i2.237 
Em 2018 foi mantida a mesma oferta de vaga chegando ao total de vinte três alunos matriculados, desse total apenas 02 alunos não apresentam diagnóstico médico fechado. No ano de 2019 foram matriculados 24 alunos matriculados, todos frequentado as ações, sendo que existe uma lista de espera com 5 crianças com indicativo de TEA aguardando para serem atendidos, desses dados são referentes ao último trimestre de 2019 (P3).

Percebe-se, então, que ano a ano o número de alunos que estão saindo do anonimato, recebendo diagnóstico e chegando as escolas regulares, necessariamente ao AEE, vem ganhando visibilidade e permitindo que esses dados sejam estudados. É importante salientar que se detectado precocemente o autismo a intervenção se dará o quanto antes, permitindo um tratamento adequado e intensivo. Isso não significa que a falta do diagnóstico inviabiliza o atendimento no CAP, através de entrevistas com a família e a escola, deve ser observado os comportamentos indicativos para o tratamento a tempo.

O processo diagnóstico não é tão simples quanto pode parecer. Além da grande diversidade de manifestações dos sintomas autísticos, existe também uma grande variedade em relação ao momento em que a criança começa a exibir cada um dos diferentes sintomas, bem como diferenças individuais no perfil desenvolvimental de cada criança e das comorbidades que podem estar presentes em diferentes casos (PESSIM; FONSECA, 2015, p. 2).

Mais importante para o CAP, que ter um diagnóstico fechado anunciando uma criança dentro do espectro do autismo é sem dúvida reconhecer que essa criança apresenta comportamento de risco para o autismo e iniciar a tempo ações de investimento para nas habilidades e no potencial de desenvolvimento que podem com a devida estimulação e tratamento alcançar.

\subsection{Das possibilidades de abordagens}

Através da criação do Projeto Político Pedagógico do CAP, a construção da proposta pedagógica para o atendimento do aluno autista foi sendo escrita dentro de uma abordagem pedagógica. Um dos maiores desafios nessa construção estava em agregar habilidades sociais práticas educacionais e comportamentais em uma proposta que atendesse a especificidade dos alunos autistas e seus familiares, como afirma a P1:

Educação, Psicologia e Interfaces, Volume 4, Número 2, p. 108-122, Abril/Junho, 2020. 
Ao longo desse tempo fomos analisando, em observações e chegamos ao consenso. Era necessário criar níveis diferentes para atender as dificuldades e potencialidades, criamos assim uma proposta dividida em 3 níveis, cada uma atendendo uma idade específica:

Nível 1 - crianças até 7 anos e que estão chegando ao CAPI (início);

Nível 2 - dos 7 aos 10 anos;

Nível 3 - crianças com mais de 10 anos e que no processo de escolarização estão saindo do fundamental I indo para o II.

$\mathrm{Na}$ análise desse discurso fica evidente a preocupação com a observação do aluno para compreensão de suas dificuldades e entender o melhor caminho para desenvolver suas potencialidades. $\mathrm{O}$ respeito as especificidades partindo da área de interesse permite o preenchimento do Plano Individual do Aluno (PDI), que deve ser elaborado pelo professor em consonância com PPP, levando em consideração que essa ferramenta individualizada apoia o professor na disponibilidade de recursos multifuncionais, na adaptação ou flexibilização curricular e no desenvolvimento de atividades que facilitam todo o trabalho durante o ano letivo.

No quesito abordagem a formação docente é uma das peças fundamentais para o desenvolvimento das potencialidades e habilidades dos alunos com TEA. É evidente que os cursos oferecidos para essa demanda são relativamente escassos na região. Então, preparar o professor para esse atendimento sempre foi um dos desafios desse trabalho como fica evidente na fala da professora:

A preparação inicialmente foi em estudos internos, formação continuada interna de buscar através de livros na literatura essa compreensão, inclusive de participar de pequenos cursos fora da cidade[...]. Em 2011 fizemos um curso de especialização, oferecido pelo Estado. Como já tínhamos um aumento, uma demanda de alunos com autismo no CAPI optamos por fazer com temática no Transtorno Global do Desenvolvimento (TGD), oferecido pela UNEB, junto com a SEC. Isso foi nos dando mais condições teóricas para desenvolver uma proposta pedagógica para atender esses alunos (P2).

Nesse trabalho pedagógico a ação de planejar respeitando a individualidade, potencialidades e reconhecendo os pontos que se deve estimular é imprescindível para o seu sucesso. No AEE, o trabalho começa individualmente, mas entendendo que o incentivo ao trabalho em grupo é fundamental para ruptura com tensões e o desenvolvimento gradual da tolerância e respeito aos seus pares. É preciso observar os comportamentos das crianças no sentido de aprender detalhes que servirão como

Educação, Psicologia e Interfaces, Volume 4, Número 2, p. 108-122, Abril/Junho, 2020.

ISSN: 2594-5343. DOI: $10.37444 /$ issn-2594-5343.v4i2.237 
indicativos de sua zona de desenvolvimento, podendo, assim, ajudá-la em seu processo de aprendizagem (LEMOS; SALOMÃO; RAMOS, 2014).

É preciso que se entenda que o processo de inclusão resulta em mudança de postura de todos os envolvidos: pais, professores, escola, estado. Uma reestruturação para que a escola receba todos os alunos e reconheça com iguais, nas suas diferenças. Onde o princípio da inclusão seja sobreposto ao princípio da integração.

\subsection{A Família como uma aliada}

Ter a família como aliada no trabalho pedagógico é uma conquista que vem gradativamente crescendo no CAP, é evidente no acompanhamento, que muitas famílias com crianças autistas não recebem o apoio necessário para seu bem-estar, tratamento e investimento socioeconômicos. Famílias que em muitas situações encontram-se esfaceladas. Uma característica dessas famílias é se sustentarem na figura da mãe como provedora e responsável por esse acompanhamento.

No CAP essa parceria se estabelece com a promoção de reuniões para acolhimento, escuta, vivências, orientações e informações, essas ações tem possibilitado a parceria da família nesse espaço, o que tem levado os familiares a entenderem como acontece o trabalho nessa instituição de AEE.

As famílias quando chegam ao CAP, chegam muito aflitas com seu filho sem saber o que fazer. Então, elas se sentiam sozinhas. Fazendo reuniões elas percebiam que não estavam só, que elas tinham outras mães, outras famílias que podiam fortalecer esse vínculo. Essas reuniões ajudam a família a se encontrar com seus filhos e estarem seguros de que eles precisam estar fora de casa e que eles podem conseguir avanços bem significativos (P1).

$\mathrm{Na}$ construção das trajetórias pedagógicas dos alunos atendidos no CAP o acompanhamento da família interfere diretamente na estimulação e aprendizagem tanto dos profissionais quanto dos alunos. Observamos o quanto é importante acolher e colaborar para que esse núcleo familiar tenha condições de contribuir na aprendizagem do sujeito autista nos diferentes contextos sociais. Quando a família é parte atuante desse processo mais uma teia é tecida dando força e sustentação ao trabalho ali desenvolvido.

Ser pai de uma criança ou adolescente com autismo não é tarefa fácil, sem dúvida. Esse exercício diário requer muito mais zelo, paciência, persistência, fiscalização, disciplina, criatividade e aumento da

Educação, Psicologia e Interfaces, Volume 4, Número 2, p. 108-122, Abril/Junho, 2020.

ISSN: 2594-5343. DOI: 10.37444/issn-2594-5343.v4i2.237 
Uma trajetória de conquistas: breves notas sobre a atuação de um Centro de Apoio Pedagógico com alunos autistas

estrutura familiar, com participação ativa de todos diretamente envolvidos (SILVA, 2012, p. 45).

É evidente que o estresse que as famílias passam quando um dos seus membros é diagnosticado com autismo muitas vezes tiram seu chão e lhes colocam numa posição de vulnerabilidade. Permitir troca de informações, apoio aos pais, irmãos e demais parentes se faz necessário para que o sujeito com autismo tenha o apoio e a família se ajuste aos desafios que possam aparecer.

É um desafio atender um aluno autista, até porque cada um que chega traz sua especificidade e fazer com que sua família entenda que apesar do transtorno ele é uma criança como outro e que pode aprender, que é possível que ele se comunique com outros da escola, desde que haja um trabalho constante e sério. [...] Temos conseguido muito resultados exitosos e um exemplo é um aluno, hoje com 14 anos tenha superado suas dificuldades na interação social e dentro do CAP tem autonomia para pedir a merenda sem precisar ser comandado (P3).

Nesses anos de funcionamento enquanto instituição pública de ensino, o CAP, vem ganhando visibilidade no atendimento a demanda de alunos no TEA e suas famílias e hoje conta com três profissionais que buscam estar em constante capacitação para que os objetivos traçados sejam alcançados com êxito.

Para nós que estamos aqui no CAP fica a ideia que sempre precisamos melhorar, mas a gente escuta das famílias que frequentam aqui e dos profissionais que encontramos lá fora colocando o CAPI como um lugar de referência, de qualidade no desenvolvimento da educação do ensino especializado. Temos feito nossa parte com todas as dificuldades, mas queremos mais, queremos melhorar, buscando uma melhor profissionalização (P2).

Fica evidente na fala da P2 o quanto o CAP é referência de um trabalho com compromisso e que esforços são feitos para que as muitas dificuldades impostas por um sistema que as vezes não permite autonomia dos profissionais sejam sanados, na busca por novos caminhos para que o atendimento ao autista seja realizado com sucesso, garantindo o seu crescimento.

As vezes achamos que estamos fazendo muito pouco em função do que temos que fazer, do que tem de se preparar, o que se vem observando é que até mesmo na produção de recursos adaptados para atender as NEE, temos avançados nesse sentido. Olhando o espaço aqui no CAP, temos muito mais recursos adaptados que se volta para um atendimento sensorial, para desenvolver a motricidade, competências cognitivas

Educação, Psicologia e Interfaces, Volume 4, Número 2, p. 108-122, Abril/Junho, 2020.

ISSN: 2594-5343. DOI: $10.37444 /$ issn-2594-5343.v4i2.237 
desses alunos, avançamos nessa produção. Também avançamos no sentido de estar elaborando melhor o planejamento as propostas de trabalho e com relação aos atendimentos com os alunos. Temos alunos inclusos no ensino comum que percebemos que dentro da limitação deles vimos que é possível essa inclusão nos espaços escolares com toda as dificuldades próprias do processo. [...]Temos outro aluno que estar aqui no CAP desde 2010, escutamos depoimentos de professores do outro município informando que ele avançou bastante; hoje ele é um outro menino no sentido de participar das atividades, de desenvolver algumas atividades do processo de alfabetização, de conseguir compartilhar, fazer amizades, de frequentar a escola a semana inteira. Então, temos experiências exitosas, até mesmo de ouvir os relatos da própria família, acredito que isso são experiências (P1).

$\mathrm{Na}$ fala das entrevistadas percebe-se que o CAP é uma instituição muito importante para as famílias dos autistas, sendo um lugar de apoio onde eles se sentem acolhidos e seguros para continuar suas jornadas que muitas das vezes é longa e pesada.

\section{CONSIDERAÇÕES FINAIS}

A partir da análise dos dados obtidos nas entrevistas podemos constatar a relevância que os profissionais do CAP e a família dos autistas tem sobre o desenvolvimento das potencialidades desses sujeitos.

$\mathrm{O}$ atendimento educacional especializado prestado aos autistas pelo CAP no decorrer desses anos de funcionamento é um serviço público que tem muito a crescer, permitindo que outras crianças, adolescente e também adultos autistas que cheguem a região Médio Rio das Contas tenham o direito assegurado.

Assim, a interação entre pais, professor e a comunidade é favorável para que o autista tenha um desenvolvimento pleno, quebrando tabus muitas vezes imposto por uma sociedade preconceituosa, que limita o processo de aprendizagem de um ser com potencial para fazer escolhas e superar as barreiras do desconhecido.

O trabalho pedagógico com o autista continua sendo um desafio diário, visto que cada indivíduo possui especificidades e dar conta de todas as estereotipias, as dificuldades de interação e comunicação traz uma grande demanda de estudo e envolvimento nesse universo que ainda é novo em estudos e publicações.

Por fim, reconhecer o papel de grande relevância que o CAP desempenha nas ações voltadas para o autista é marcar um percurso na história da comunidade local, história que tem muitas linhas que ainda serão escritas e muitos autistas beneficiados com esses atendimentos pedagógicos. Garantir o que preza o Projeto Político Pedagógico da 
escola continuará sendo um desafio muito grande pois, assegurar um AEE de qualidade, fortalecendo a autonomia e favorecendo a inserção desses alunos nos diversos ambientes sociais é tarefa árdua mais necessários a todos os atores dessa peça chamada vida.

\section{REFERÊNCIAS BIBLIOGRÁFICAS}

BAHIA. Secretaria Estadual de Educação. Diretrizes da Educação Inclusiva no Estado da Bahia (Pessoas com Deficiência, Transtornos Globais do Desenvolvimento e Altas Habilidades/Superdotação). Salvador: SEC, 2017

BRASIL, Ministério da Educação. Decreto Legislativo no 186 de 09 de julho de 2008. Aprova o texto sobre os Direitos das Pessoas com Deficiência e de seu Protocolo Facultativo, assinados em Nova Iorque, em 30 de março de 2007. Brasília, 2008. Disponível em: www.planalto.gov.br/ccivil_03/congresso/DLG-186.2008. Acesso em 26 de jul. 2018

CUNHA, Eugênio. Autismo e Inclusão: psicopedagogia e práticas educativas na escola e na família. $3^{\mathrm{a}}$ ed. Rio de Janeiro: Wak Ed, 2011.

FERREIRA, Tereza. VORCARO, Angêla. O tratamento psicanalítico de crianças autistas: diálogos com múltiplas experiências. Autêntica, Minas Gerais, 2016.

GARCIA, Rosalba Maria Cardoso. Política de educação especial na perspectiva inclusiva e a formação docente no Brasil. Rev. 2013. Disponível em:

http://www.scielo.br/pdf/rbedu/v18n52/07.pdf acesso em novembro de 2019.

GOMES, Márcio. Construindo as trilhas para a inclusão. Petrópolis, RJ: Vozes, 2009.

KASSAR, Mônica Carvalho Magalhães. Educação especial no Brasil: desigualdades e desafios no reconhecimento da diversidade. Rev. Educ. Soc. Campinas, V. 33, 2016. Diponível em: http://www.scielo.br/pdf/es/v33n120/10.pdf data de acesso novembro de 2019.

KOCH, Ingedore Villaça. O texto e a construção dos sentidos. $8^{a}$ ed. São Paulo: Contexto, 2005.

LEMOS, Emellyne Lima de Medeiros Dias. SALOMÃO, Nádia Maria Ribeiro. RAMOS, Cibele Shírley Agripino. Inclusão de crianças autistas: um estudo sobre interações sociais no contexto escolar. 2014. Disponível em: www.scielo.br/scielo.php?script=sci arttext\&pid=S1413-65382014000100009. Acesso em 26 jul. 2019.

MURATORI, Filippo. O diagnóstico no autismo: guia prático para pediatras/tradução de Camilla Carmelo de Siervi e Daniele de Brito Wanderley. Salvador: NIIP, 2014.

Educação, Psicologia e Interfaces, Volume 4, Número 2, p. 108-122, Abril/Junho, 2020.

ISSN: 2594-5343. DOI: $10.37444 /$ issn-2594-5343.v4i2.237 
PESSIM, Larissa Estanislau. FONSECA, Bárbara Cristina Rodrigues. Transtornos do Espectro Autista: importância e dificuldade do diagnóstico precoce. 2015. Disponível em: www.faef.revista.inf.br/imagens_arquivos/pnnWsCHLoL9zOLE-2015-3-3-14-728.pdf. Acesso em 14 agost.2019.

PIMENTA, Selma Garrido; GHEDIN, Evandro; FRANCO, Maria Amélia Santoro (Orgs.). Pesquisa em Educação: alternativas investigativas com objetos complexos. São Paulo: Edições Loyola, São Paulo, 2006. p. 25-64.

SILVA, Ana Beatriz Barbosa. Mundo Singular: entenda o autismo. Rio de Janeiro: Fontanar, 2012.

WILlianMS, Chris. Convivendo com Autismo e Síndrome de Asperger: Estratégias Práticas para pais e profissionais. São Paulo: M.Books do Brasil, 2008.

\section{Credenciais da/os autora/es}

BASTOS, Solange Barboza. Diretora no Centro de Apoio Pedagógico em Ipiaú na Bahia. Graduada em Educação Física (FM), Especialista em educação inclusiva (FCSA). E-mail: socasbastos@hotmail.com

SANTOS, Antonia Vieira. Professora na Universidade do Estado da Bahia - UNEB (Campus XXI). Graduada em Psicologia (UFRB), Mestre em Ciências Sociais (UFRB) e Doutoranda em Psicanálise, saúde e sociedade pela Universidade Veiga de Almeida (UVA). E-mail: $\underline{\text { s.antoniavieira@gmail.com }}$

Endereço para correspondência: Solange Barboza Bastos. Avenida Getúlio Vargas, 303, Centro, Ipaiú- BA. CEP: 45.570.000. E-mail: socasbastos@ hotmail.com

Como citar este artigo (Formato ABNT): BASTOS, Solange Barboza; SANTOS, Antonia Vieira. Uma trajetória de conquistas: breves notas sobre a atuação de um Centro de Apoio Pedagógico com alunos autistas. Educação, Psicologia e Interfaces, v. 4, n.2, p. 108-122, 2020. Doi: 10.37444/issn-2594-5343.v4i2.237

Recebido: 07/02/2020.

Aceito: 20/03/2020. 